\title{
Damage Control Surgery with Pad Packing for Active Bleeding in Crushing Wound of Perineum and Amputated Leg Stump
}

\author{
Wu Seong Kang, M.D.
}

Department of Trauma Surgery, Wonkwang University Hospital, Iksan, Korea

\section{A 67-year-old man experienced crushing injury. His left leg} had been sucked in the wheel of a tractor. The patient's systolic blood pressure and hemoglobin levels were $50 \mathrm{mmHg}$ and 7.5 $\mathrm{g} / \mathrm{dl}$, respectively, upon admission. The large defect of leg wound was considered to need to be amputated above the knee. A large volume of bloody discharge was observed in the perineal wound and leg stump wound. After the femoral vein and artery were ligated during amputation surgery, to control the bloody oozing pad packing to perineal and thigh stump wounds was performed and approximation with suture was done to compress the wound (Fig. 1). After pad packing, the bloody discharge has been stopped without additional angioembolization. Likely other abdominal injuries, the hemodynamically unstable crushing perineal and leg stump were treated safely by damage control surgery with pad packing [1,2].

\section{Conflicts of Interest}

Received August 10, 2018, Revised September 27, 2018

Accepted September 27, 2018

Correspondence to: Wu Seong Kang, M.D.

Department of Trauma Surgery,

Wonkwang University Hospital, 895

Muwang-ro, Iksan 54538, Korea

Tel: +82-63-859-2602, Fax: +82-63-859-2029,

E-mail: wuseongkang@naver.com ORCID:

http://orcid.org/0000-0003-0136-4458

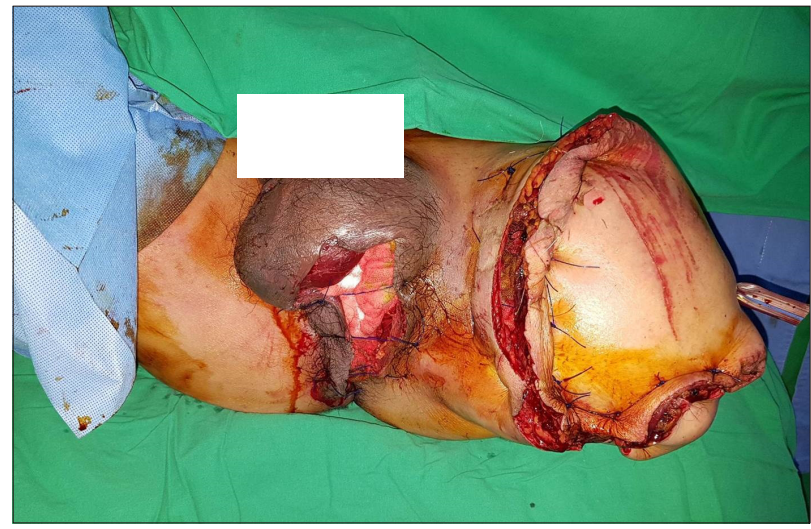

Fig. 1. Pad packing to perineal wound and leg stump wound (Informed consent was taken).

No potential conflict of interest relevant to this article was reported.

\section{References}

1. Ball CG. Damage control surgery. Curr Opin Crit Care 2015;21:538-43.

2. Shapiro MB, Jenkins DH, Schwab CW, Rotondo MF. Damage control: collective review. J Trauma 2000;49:969-78.

Copyright (C) 2018 by Korean Society of Acute Care Surgery

(c) This is an Open Access article distributed under the terms of the Creative Commons Attribution Non-Commercial License (http://creativecommons.org/licenses/by-nc/4.0) which permits unrestricted non-commercial use, distribution, and reproduction in any medium, provided the original work is properly cited. 